\title{
Study on Aesthetics-cored Music Education Reform
}

\author{
Boyuan Song ${ }^{1}$, Junwei Ren ${ }^{2}$ \\ ${ }^{1,2}$ School of Humanities, Jiangxi University of Traditional Chinese Medicine, Nanchang, 330004 , \\ China
}

Key words: Aesthetics, Music education, Measure.

\begin{abstract}
Aesthetics is the essential pursuit and core function of art. Aesthetic education also needs to be valued in music art field. The core position of aesthetic education in music education has been ignored in recent years. Thus, based on stressing the importance of aesthetic education, this paper aims at development appeal of music education and deeply discusses how to focus on aesthetic education to effectively promote music education reform and development and overall improve aesthetic nature and effectiveness of music education.
\end{abstract}

\section{Introduction}

Music as an art has multidirectional functions, including entertainment, education and cultural exchange etc. The feeling sand experience of receivers and subjects of music art for music are the final fate of expression and development of music art. Subjects can appreciate, study and transmit music and the emotion with the aesthetic attitude, which is the important precondition of achieving other functions of music. From the perspective of music education, the objective of music art education is to cultivate students' aesthetic ability and let them have art foundation of appreciating beauty and creating beauty. For sustainable development of music education, it is necessary to ponder over development path through regarding aesthetics as the core. This is the basic thought of music education reform.

\section{Aesthetics-cored music education and its basic connotation}

Aesthetics-cored music education emphasizes to highlight the critical nature of aesthetics in mainstream music education, and deems aesthetics as the principal line. It is divided as artistic aesthetic education and does not belong to the scope of music education. Aesthetics-cored music education means the aim of music education activity is to cultivate students' ability to discover beauty, appreciate beauty and create beauty, and guide students to take active part in aesthetic activity.

Aesthetics-cored music education is still based on school environment. It still applies common music education mode and just regards aesthetic education as the second important education content except professional music knowledge and skill education. The position of both no longer lays particular emphasis in traditional educational idea, but both receive the same degree of importance and are mutually related. Both play a role together to promote cultivation of music talents. In this music education mode, improvement of students' aesthetic judgment is the final purpose, while the expansion of professional music knowledge and the skill promotion are the basic preconditions of gaining aesthetic judgment. A higher learning level is students' possession and improvement of aesthetic judgment. It more stresses students' perceptual ability and makes students gradually grow to individuals more harmonious with social development in music study. 


\section{Advancement of aesthetics-cored music education}

\section{Beneficial to helping students enhance aesthetic judgment from psychological level}

The essence of aesthetic judgment is human comprehensive psychological ability. Under multi-angle stimulus of external aesthetic object, people perceive beauty from psychological level and arouse individuals' self-feeing, imagination and creation for aesthetic object under the action of psychological development law. When it is applied in music art field, music aesthetics is individual music perception process and imagination and creation process. Music stimulus of human perceptivity forms response through auditory sense. The music of different organization and expression means penetrates human sense organs to form specific auditory image and also generates corresponding influence on human emotion. Secondly, psychological activity in music is also embodied in the occurrence of association and imagination. Music art often owns specific connotation. Under external manifestation pattern, individuals need to go deep into the connotation of music works through necessary association and imagination. Students make association and imagination run through music teaching to enhance emotional experience of art works. This is also the important foundation of students' art creation. Aesthetics-centered music education lays psychological foundation for objectively cultivating students' aesthetic judgment, while cultivation of aesthetic judgment is a recessive and long-term process. Only when aesthetics serves as the core for education can sufficient time and space be provided for achieving this teaching effect.

\section{Aesthetics-cored music education motivates and cultivates students' innovative thinking}

Innovative thinking plays a unique and essential role in music appreciation and creation. Music works bring students with sensorial stimulus and psychological experience. Aesthetics-cored music education highlights its education advantage of brain development. Sensory stimulus brought by music to students gradually transforms to cultivation and enhancement of students' touch sensitivity and coordination under aesthetics-cored education mode. These qualities are very important in art creation and have positive promotion role in development and cultivation of students' innovative thinking. Music education sticks to deeming aesthetics as the core and can create pleasing atmosphere in teaching. Under the relaxing state, students can burst out the spark of thinking and improve art creativity.

\section{Aesthetics-cored music education strongly shapes students’ perfect personality}

Art works often show the true, the good and the beautiful of objective world. In music art field, excellent works contain aesthetic connotation, while traditional education mode puts teaching center in professional knowledge and skills and places aesthetic education of works in the secondary position. If such teaching mode is implemented for a long term, students' comprehensive development and especially personality growth are influenced. Meanwhile, the shaping function of music education for students' personality is weakened. To stress the importance of aesthetics in music education is to emphasize students can pay more attention to aesthetic explanation and expression of human nature, emotion and value in music appreciation. Under education guidance, students think independently, form self-cognition of world and human nature and accumulate more experience for shaping self-personality.

Aesthetics-cored music education attaches importance to student individuals.

\section{Aesthetics-cored music education is an effective approach to achieve reform and self-development}

With continuous exploration and breakthrough of higher music education field in recent years, China has gained certain effect in music education and especially aesthetic education reform, but the whole music education still develops in traditional track. Reexamination and positioning of aesthetic education in reform fail to be materially reformed and broken through. In current stage, firstly, the 
center of music education is still professional knowledge teaching. Theorization becomes the main feature of music education. Aesthetic education is still in the edge position and fails to develop. This makes music education and music learning single. Students not just lose learning interest, but also have no objective development space. Secondly, aesthetic education has been valued continuously and actively introduced in music education in recent years, but its development is still limited to theoretical level and is not reflected in the specific implementation. Many universities have deviation and hysteretic nature in consciousness system and lack initiative in practice. Therefore, we need to really promote and implement aesthetic education in music education practice and take effective measures to overall construct aesthetics-cored music education system.

\section{To transform educational concept, attach importance to and deeply cognize aesthetic core in music education}

Education view and teaching idea as the content of consciousness level have direct influence on teaching practice. For music education reform and development, scientific teaching idea can guide universities and teachers to stick to correct direction and development thought in education and form organic unity of consciousness and practice. Aesthetics-cored music education tends to perceptual artistic aesthetics education. It is required to hold such view, pay attention to aesthetic education in music art and put more teaching emphases in this aspect during treating this education form. It is required to promote aesthetics-cored music education to achieve benign transformation and development. The primary point is to enhance view transformation at consciousness level, see aesthetic function of music art, establish aesthetic education view, actively introduce educational function mode in music education, confirm the core position of aesthetics in music education, lead students to perceive and appreciate the beauty in music works in teaching and improve students' aesthetic taste and judgment. Educational concept transformation is also reflected in correct guidance of students' music study and making students cognize music aesthetic nature. During learning professional music knowledge, students can generate interest in emotional charm and personality expression in music. This can help students more actively learn music and generate learning enthusiasm.

\section{To overall improve aesthetic education ability of music teachers}

Teachers as a subject in education play a critical role in educational reform. They are executors and pushers of educational reform measures. Whether teachers can correctly comprehend reform intention and achieve reconstruction and thinking of self-teaching system, which is crucial for music education reform and development. Thus, teachers need to think how to stress and highlight aesthetic education in music education, play the leading role in music class and achieve role expansion from knowledge transmitter to beauty spreader. Firstly, innovative change should be achieved in teacher's teaching concept. Teachers need to deeply cognize and pay attention to innovation features of music art and its education role in motivating students' creativity, actively refer to domestic and oversea advanced experience, form innovation mechanism in macroscopic educational pattern and specific teaching method, respect and value students' dominant role. Secondly, music education should be regarded as a process, instead of pursuing scores through examinations and evaluation. Teachers should let students receive more aesthetic education in procedural and dynamic teaching process, pay attention to students' emotional absorption, guide them to deeply experience the true, the good and the beautiful of music works and motivate students' music potential from a deep level while they master knowledge and skills.

Students' potential music ability and especially sensitivity play a critical role in cultivating music accomplishment. Traditional music education mostly stays on technical level. Students have music skills, but lack necessary art sensibility and aesthetic judgment. Thus, it is difficult for them to break through themselves and achieve material improvement of professional music level. Such situation is an obstacle and restricts achievement of higher-level education value of music education. For teachers, they need to improve their teaching skills and professional knowledge reserve in aesthetic 
education, own the ability to deeply appreciate music works, continuously expand their knowledge base and achieve real-time update of educational concept, teaching method and professional knowledge system.

\section{To innovate music teaching method system and improve teaching efficiency}

Aesthetics-cored music education reform and its development need teaching method. Teaching method system can achieve self-development and give full play to its positive promotion role for music education only when it innovates according to new education demand. To be more specific, the improvement of music teaching method needs to start from the following aspects. Firstly, it is required to highlight the role of auditory feeling and soul experience in music teaching, apply inquiry method and cooperation method to give play to students' initiative in music learning. This can provide students with sufficient space for self-thinking and inquiry and cultivate their creative thinking. Secondly, modern teaching means become the major carrier of teaching efficiency improvement in modern education reform. Thus, multimedia teaching means should be fully utilized in music education reform, and information technology and other advanced technologies should be used to present music works more vividly and flexibly to help students learn, appreciate and analyze music works more effectively and conveniently. The application of diversified teaching means can create more vivid teaching situation, make students have more thinking and learning passion in relaxing and pleasant teaching atmosphere, motivate their innovative thinking and music potential to the largest extent and improve teaching quality. Thirdly, richness of music teaching activity should be valued. Music activities in and outside classroom and campus can provide a good platform for students' earning and self-improvement. Teachers should attach importance to teaching significance of these activities, develop diversified activities and create favorable external environment for students’ music learning and especially music practice.

\section{Conclusion}

Music as one of the most general and popular art forms in human culture development history has its unique art charm. Education as an important approach of art inheritance receives great attention. Music education in modern society gradually gains systematic improvement, but development hysteresis still exists. The regression and highlighting of aesthetic function become the main problems of current music education reform. Aesthetic education needs to gain more attention in music education. Meanwhile, educators should acti9vely think and explore effective development approaches of music aesthetic education from multiple levels.

\section{References}

[1] Song Zijie, On aesthetics-cored music education reform . Contemporary Music, 2015(23).

[2] Ma Qiaomei, Aesthetics-cored music education reform . Music Space, 2015(03).

[3] Zi Liping, Re-reflection of aesthetics-cored music education . Explorations In Music, 2016(01). 